\title{
Sustained Release and Cytotoxicity Evaluation of Carbon Nanotube-Mediated Drug Delivery System for Betulinic Acid
}

\author{
Julia M. Tan, ${ }^{1}$ Govindarajan Karthivashan, ${ }^{2}$ Palanisamy Arulselvan, \\ Sharida Fakurazi, ${ }^{2,3}$ and Mohd Zobir Hussein ${ }^{1}$ \\ ${ }^{1}$ Materials Synthesis and Characterization Laboratory, Institute of Advanced Technology (ITMA), Universiti Putra Malaysia, \\ 43400 Serdang, Selangor, Malaysia \\ ${ }^{2}$ Laboratory of Vaccine and Immunotherapeutics, Institute of Bioscience (IBS), Universiti Putra Malaysia, \\ 43400 Serdang, Selangor, Malaysia \\ ${ }^{3}$ Department of Human Anatomy, Faculty of Medicine and Health Sciences, Universiti Putra Malaysia, \\ 43400 Serdang, Selangor, Malaysia
}

Correspondence should be addressed to Mohd Zobir Hussein; mzobir@upm.edu.my

Received 11 July 2014; Accepted 4 September 2014; Published 15 September 2014

Academic Editor: Krasimir Vasilev

Copyright (C) 2014 Julia M. Tan et al. This is an open access article distributed under the Creative Commons Attribution License, which permits unrestricted use, distribution, and reproduction in any medium, provided the original work is properly cited.

\begin{abstract}
Carbon nanotubes (CNTs) have been widely utilized as a novel drug carrier with promising future applications in biomedical therapies due to their distinct characteristics. In the present work, carboxylic acid-functionalized single-walled carbon nanotubes (f-SWCNTs) were used as the starting material to react with anticancer drug, BA to produce f-SWCNTs-BA conjugate via $\pi-\pi$ stacking interaction. The conjugate was extensively characterized for drug loading capacity, physicochemical properties, surface morphology, drug releasing characteristics, and cytotoxicity evaluation. The results indicated that the drug loading capacity was determined to be around $20 \mathrm{wt} \%$ and this value has been verified by thermogravimetric analysis. The binding of BA onto the surface of f-SWCNTs was confirmed by FTIR and Raman spectroscopies. Powder XRD analysis showed that the structure of the conjugate was unaffected by the loading of BA. The developed conjugate was found to release the drug in a controlled manner with a prolonged release property. According to the preliminary in vitro cytotoxicity studies, the conjugate was not toxic in a standard fibroblast cell line, and anticancer activity was significantly higher in A549 than HepG2 cell line. This study suggests that f-SWCNTs could be developed as an efficient drug carrier to conjugate drugs for pharmaceutical applications in cancer chemotherapies.
\end{abstract}

\section{Introduction}

The revolutionary development of drug delivery technology has become one of the most prominent areas in biomedical science, contributing to a profound beneficial impact on human healthcare. This interdisciplinary technology can be defined as a method or process of delivering drugs and biomolecules to the targeted site of the cell for a specific period of time (sustained release function) with reduced side effect. The current methods of conventional drugs administered via liquids or tablets are generally less efficient and suffered from poor biodistribution, low solubility, long-term toxicity, and limited drug efficacy due to partial biodegradation, swelling, and erosion [1]. This has caused the pharmaceutical industry to develop novel drug delivery systems using a wide range of biocompatible drug carriers with the aim to improve therapeutic efficacy and reduced toxicity. In meeting this demand, various forms of efficient and biocompatible drug delivery systems have been developed extensively and can be generally classified into four major categories: nanomaterials [2-4], viral carriers $[5,6]$, organic cationic compounds $[7,8]$, and recombinant proteins $[9,10]$.

In the recent years, nanomaterials such as carbon nanotubes (CNTs) have been receiving considerable amount of attention as a new nonviral carrier alternative [11-13] compared to viral and cationic carrier. These allotropes of carbons are extensively studied and investigated as novel drug delivery vehicles due to their good biocompatibility, ultrahigh surface area, good mechanical strength yet ultralight weight, low cytotoxicity, and excellent chemical and thermal stability. 
Furthermore, their outer surface can be chemically functionalized with biocompatible materials [14] whilst inner volume allows the loading of small biomolecules such as proteins and genes for effective drug delivery [15]. Recently, it was reported that chemically functionalized CNTs can be utilized as a novel form of drug carrier by attaching different range of functional groups to their sidewalls [16]. The research team discovered that the functionalized CNTs were able to cross cell barriers in mice through the enhanced permeability and retention effect without causing any harm to the cell under conditions which would normally prevent or delay this biological process. Equipped with all these unique advantages of CNTs and their tremendous breakthroughs in biomedical nanotechnology [17-19], it is no doubt that CNTs can be used as a promising novel drug targeted delivery system for advance therapeutic treatment.

Betulinic acid (3 $\beta$-hydroxy-lup-20(29)-en-28-oic acid, Figure 1) is a naturally occurring pentacyclic lupane-type triterpene extracted from numerous botanical sources found widely distributed in the plant kingdom. Among them, the birch tree, Betula alba, can be considered as one of the highly reported sources of betulinic acid (BA) [20]. It has been used traditionally as a folk remedy by the Native Americans to treat intestinal problems like dysentery and diarrhoea. Recent studies reported that BA possesses many favourable therapeutic activities such as anticancer, hepatoprotective potential, antimalarial, anti-inflammatory, antihuman immunodeficiency virus (HIV), anthelmintic, and antioxidant effects [21-25]. BA was also well known for its high selective cytotoxic activity against human melanomaderived cell lines [26] as well as other types of cancerous tumour [27-29]. Healthy normal cells like peripheral blood lymphoblasts, melanocytes, normal human fibroblasts, and astrocytes were also reported to be resistant against BA treatment in vitro [30]. However, its optimum potential is greatly limited by poor solubility in aqueous solvents. As such, an ideal delivery system can further enhance the bioavailability of BA as a potent anticancer agent.

Pristine CNTs (without functionalization) are generally water insoluble and easily form bundles through strong van der Waals forces and, therefore, they cannot be dispersed effectively in most aqueous solutions. They pose a great barrier for drug delivery applications because the insoluble CNTs may cause aggregation inducing characteristic cell changes and apoptosis when administered into human body. This is further supported by studies showing that raw CNTs were observed to accumulate mainly in the liver, lungs, and spleen of the animals [31] while the chemically functionalized ones were found to be excreted in urine and faeces of the animals [32]. Thus, researchers strongly believed that side wall functionalization using carboxylic acid is one of the most powerful approaches to improve the solubility of CNTs $[33,34]$.

To the best of our knowledge, this is the first time we report on the conjugation of anticancer drug, BA, by using a more suitable delivery system, namely, carboxylic acidfunctionalized single-walled carbon nanotubes (f-SWCNT), to enhance the bioavailability of BA. The aim of this work was to evaluate the drug loading and release properties as

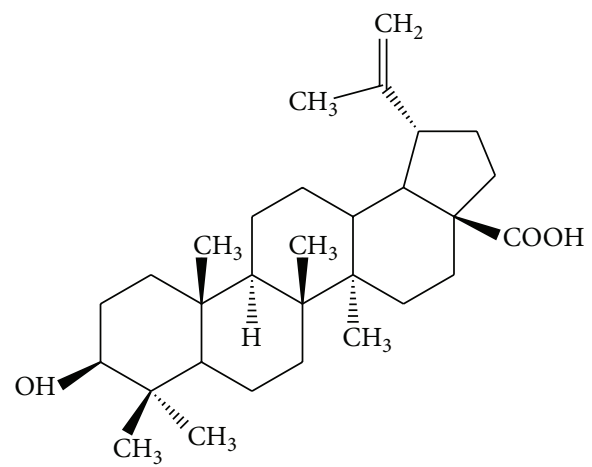

FIGURE 1: Molecular structure of betulinic acid.

well as the release kinetics of the synthesized conjugate. In addition, we also studied the chemical structure and surface morphology of the resulting conjugate. Finally, in order to evaluate the cytotoxicity effects of the conjugate, two human cancer cell lines (HepG2 and A549) were used in comparison with normal fibroblast cell lines (3T3).

\section{Materials and Methods}

2.1. Materials and Characterizations. BA ( $\geq 98 \%$ as determined by $\mathrm{HPLC}, \mathrm{C}_{30} \mathrm{H}_{48} \mathrm{O}_{3}, 456.70 \mathrm{~g} / \mathrm{mol}$ ) was purchased from Sigma-Aldrich (Saint Louis, USA). The short f-SWCNTs with a diameter of $1-2 \mathrm{~nm}$ and a purity of $>90 \%$ used in the current work are commercially available from Chengdu Organic Chemicals Co. Ltd. (Chengdu, China). Methanol of 99.8\% purity was supplied by HmbG Chemicals (Germany) and used as solvent for BA. All chemicals and solvents were of analytical grade and used as received.

The samples (BA, f-SWCNTs, and f-SWCNTs-BA) were characterized by ultraviolet-visible spectrophotometer (UVvis, Lambda 35, Perkin Elmer, Boston, USA), Fourier transform infrared spectroscopy (FT-IR, model Smart Orbit, Thermo Nicolet Nexus FTIR, Vernon Hills, USA), thermogravimetric analysis (TGA, Q500, TA Instruments, New Castle, DE), Powder X-ray diffraction (PXRD-6000, Shimadzu, Kyoto, Japan), Raman (RamanMicro 200, Perkin Elmer, Waltham, USA), and field emission scanning electron microscope (FESEM, JSM-7600F, JEOL, Tokyo, Japan).

2.2. Calibration Curve. The standard solutions of BA were prepared as follows. A stock solution $(16 \mathrm{~mL})$ was prepared by dissolving $8 \mathrm{mg}$ of pure BA in methanol to obtain the drug concentration of $0.5 \mathrm{mg} / \mathrm{mL}$. Aliquots of standard solutions of BA were transferred into a $20 \mathrm{~mL}$ volumetric flask and the mixture was allowed to stand for $7 \mathrm{~min}$ at room temperature before recording the absorbance. The absorbance (A) was spectrophotometrically analyzed at $210 \mathrm{~nm}$ against reagent blank using UV-vis spectrophotometer where the drug presents a maximum absorption. A calibration curve was plotted to get the linearity in the concentration range of $0.0-0.5 \mathrm{mg} / \mathrm{mL}$ and regression value. The curve is described by the regression equation $A=7.4717 x(\mathrm{mg} / \mathrm{mL})+0.0253$, where $A$ is the absorbance and $x$ is the concentration in $\mathrm{mg} / \mathrm{mL}$, with a correlation coefficient $\left(R^{2}\right)$ of 0.9937 . 
2.3. Preparation of $f$-SWCNTs-BA Conjugate. The purchased $\mathrm{f}$-SWCNT (20 mg) was dispersed in BA solution $(5 \mathrm{mg}$ in $99.8 \%$ methanol, $40 \mathrm{~mL}$ ) and sonicated for 30 minutes. Subsequently, the dispersion was magnetically stirred at room temperature for 22 hours using a magnetic bar to facilitate loading of BA. Thereafter, the mixture was subjected to centrifugation at $4000 \mathrm{rpm}$ for 15 minutes and then washed with methanol and followed by deionized water three times and centrifuged to remove free/unbound BA. The supernatant was collected to determine the drug loading capacity, whereas the solid sample was dried at $60^{\circ} \mathrm{C}$ in an oven for 24 hours to obtain $\mathrm{f}-\mathrm{SWCNTs-BA}$ conjugate. The resulting f-SWCNTsBA conjugate was stored at room temperature in a vacuum desiccator for further use of studies.

2.4. Assessment of $f$-SWCNTs Loading with BA. The amount of free/unbound BA weight ( $\left.W_{\text {unbound BA }}\right)$ in the solution was quantified by measuring the absorbance at $210 \mathrm{~nm}$ relative to a calibration curve prepared under the same condition [35, 36] using a UV-vis spectrophotometer (Figure 2). The drug loading capacity was calculated as follows:

$$
\begin{aligned}
& \text { Drug loading capacity (\%) } \\
& =\frac{\left(W_{\text {feed BA }}-W_{\text {unbound BA }}\right) 100}{W_{\text {feed BA }}} .
\end{aligned}
$$

The drug loading capacity of BA was estimated to be $\sim 20 \%$. A scheme of the drug conjugation is presented in Scheme 1.

2.5. Measurement of BA Controlled Release In Vitro. The release profiles of BA from the f-SWCNTs were performed in human body-simulated phosphate buffered saline (PBS) solutions at pH 7.4 and $4.8[37,38]$. PBS is a water-based salt solution containing different kinds of anions like $\mathrm{Cl}^{-}$, mono phosphate $\mathrm{H}_{2} \mathrm{PO}_{4}{ }^{-}$, and dibasic phosphate $\mathrm{HPO}_{4}{ }^{2-}$. Briefly, about $1 \mathrm{mg}$ of $\mathrm{f}-\mathrm{SWCNTs}-\mathrm{BA}$ conjugate was dispersed into $3.5 \mathrm{~mL}$ of release media with specific $\mathrm{pH}$ value. Maximum absorbance of $210 \mathrm{~nm}$ was selected and the accumulated release amount of BA into the solution was determined at preset time intervals using a UV-vis spectrophotometer.

2.6. Cell Lines and Cell Viability Tests. 3T3 (normal standard fibroblast cell line), HepG2 (human liver hepatocellular carcinoma cell line), and A549 (human lung adenocarcinoma epithelial cell line) were purchased from American Type Culture Collection (Manassas, VA, USA). The cells were cultured under standard cell culture conditions $\left(37^{\circ} \mathrm{C}\right.$ in a humidified atmosphere of 95\% room air/5\% $\mathrm{CO}_{2}$ ) in RPMI 1640 medium supplemented with $10 \%$ heat inactivated fetal bovine serum (FBS) and $1 \%$ penicillin (100 units $/ \mathrm{mL}$ )/streptomycin $(100 \mu \mathrm{g} / \mathrm{mL})$. Cells were subcultured in $75 \mathrm{~cm}^{2}$ culture flasks or in appropriate plates and used for seeding and treatment after reaching approximately $80 \%$ confluence.

The MTT [3-(4,5-dimethylthiazol-2-yl)-2,5-diphenyltetrazolium bromide] assay, as previously described in [39], was used to measure cell viability. In brief, all the normal and cancer cells were seeded at a density of $1 \times 10^{4}$ cells/well

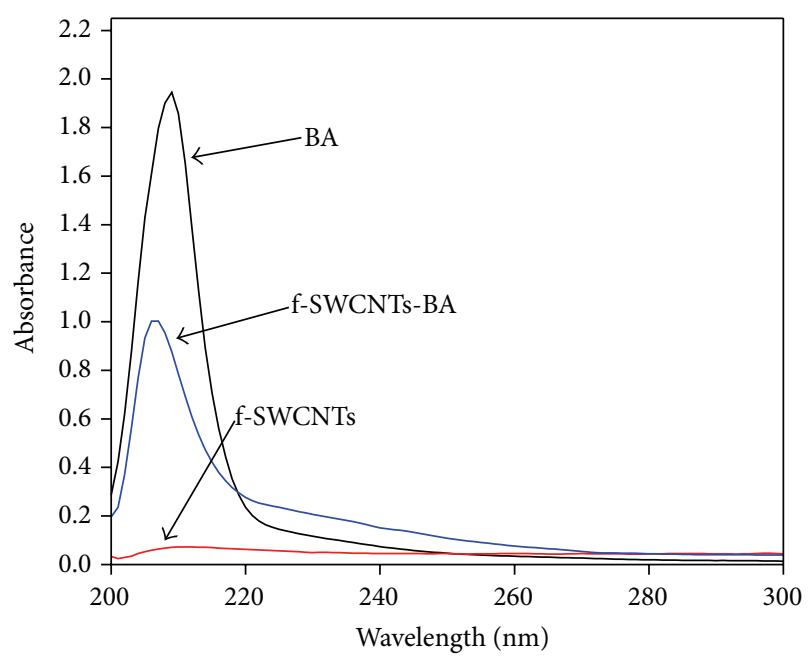

FIGURE 2: UV-vis absorption spectra of pure BA, the supernatant of f-SWCNTs-BA conjugate, and f-SWCNTs.

in 96-well culture plates in $200 \mu \mathrm{L}$ of culture medium and incubated at $37^{\circ} \mathrm{C}$ to assure cell attachment. After $24 \mathrm{~h}$, the cells were treated with BA, f-SWCNTs, and f-SWCNTs-BA conjugate prepared at various concentrations and the treated cells were incubated for $72 \mathrm{~h}$. Subsequently, $20 \mu \mathrm{L}$ of MTT solution $(2.5 \mathrm{mg} / \mathrm{mL})$ in PBS solution was added to each well, and then the plates were further incubated at $37^{\circ} \mathrm{C}$ for $3 \mathrm{~h}$. The solution in each well was discarded by suction and replaced by $100 \mu \mathrm{L}$ of dimethyl sulfoxide and vigorously mixed to dissolve the reacted dye. After 30 min of incubation, the absorbance was measured at a wavelength of $575 \mathrm{~nm}$ using a microplate reader (EL 800X, Bio-Tel Instruments Inc., Winooski, VT, USA). All assays were done in triplicate and the cytotoxicity results were expressed as the percentage of cell viability with respect to control cells.

\section{Results and Discussions}

3.1. Characterization of $f-S W C N T s-B A$ Conjugate. The conjugate was extensively characterized by FTIR, TGA, XRD, Raman, and FESEM. FTIR is a powerful and sensitive infrared spectroscopy which is used to verify the conjugation of BA on f-SWCNTs. In this study, FTIR was performed using compressed $\mathrm{KBr}$ pellet method and the samples were recorded in the 4000 to $500 \mathrm{~cm}^{-1}$ range. As presented in the spectra of f-SWCNTs-BA (Figure 3), the absorption peaks observed at 3434 and $1627 \mathrm{~cm}^{-1}$ correspond to the absorption peaks of BA at 3449 and $1641 \mathrm{~cm}^{-1}$. These peaks are attributed to the typical stretching vibrations of $\mathrm{C}=\mathrm{O}$ and $\mathrm{O}-\mathrm{H}$, suggesting the presence of $-\mathrm{COOH}$ functional group either from BA molecule or from f-SWCNTs. The peaks at 2916 and $1387 \mathrm{~cm}^{-1}$ imply both the asymmetric and symmetric $\mathrm{C}-\mathrm{H}$ stretching vibrations which arise from the methyl and methylene group of BA [40], respectively, while the absorption peak at $545 \mathrm{~cm}^{-1}$ could be due to the characteristic absorption of aromatic compound from the benzene rings of BA. 

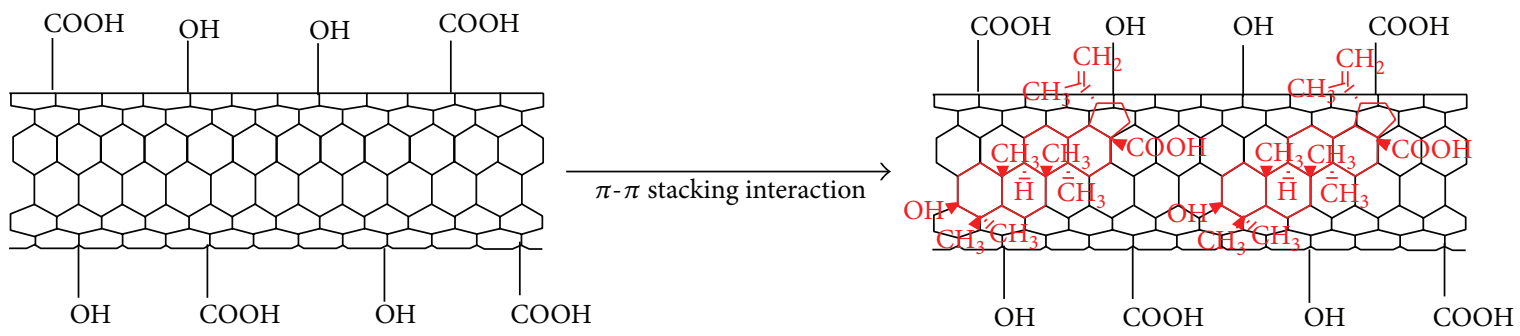

Scheme 1: Proposed reaction scheme for the functionalization of BA molecules onto the f-SWCNTs nanocarrier via $\pi-\pi$ stacking interaction.

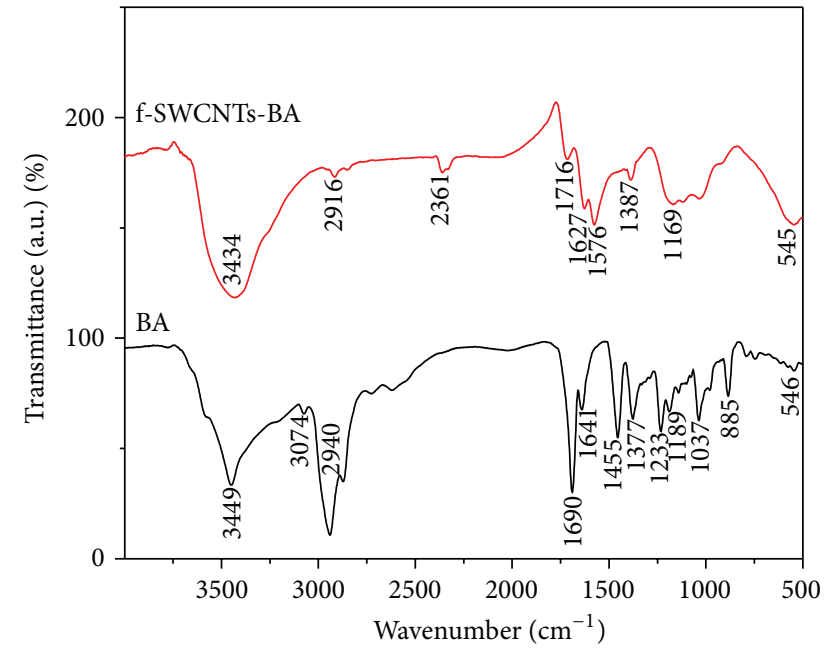

FIGURE 3: FTIR transmission spectra of f-SWCNTs-BA and BA.

To determine the actual drug loading, TGA was used and the samples were heated from room temperature up to $1000^{\circ} \mathrm{C}$ with a heating rate of $10^{\circ} \mathrm{C} / \mathrm{min}$ under a nitrogen purge of $40 \mathrm{~mL} / \mathrm{min}$. The TGA curves of f-SWCNTs and f-SWCNTsBA are presented in Figure 4. In the total heating process, the f-SWCNTs exhibited a weight loss of about $22.5 \mathrm{wt} \%$ (Figure 4(a)), while the f-SWCNTs-BA lost approximately $44.4 \mathrm{wt} \%$ of weight (Figure 4(b)). The first weight loss interval below $200^{\circ} \mathrm{C}$ of both samples was mainly due to the evaporation of adsorbed water [41]. At higher temperatures the weight loss was attributed to the thermal decomposition of the loaded drug, BA. The amount of drug loaded onto the f-SWCNTs is about $21.9 \mathrm{wt} \%$ (Figure 4(b)) and this value is nicely agreed with the UV-vis analysis, which was calculated to be about $20 \mathrm{wt} \%$.

The PXRD analysis of the samples was carried out by adjusting the radiation $\mathrm{CuK}_{\alpha}$ at $30 \mathrm{kV}$ and $30 \mathrm{~mA}$ for recording the PXRD diffractograms between 2 and $90^{\circ}$. This nondestructive analytical method is a valuable tool for characterizing the CNTs and surface functionalization. Figure 5 shows the PXRD patterns for f-SWCNTs, f-SWCNTs-BA, and free BA, respectively. The PXRD analysis of f-SWCNTs and f-SWCNTs-BA shows that there was no change in the tubular structure of the nanotubes. This indicates that the drug loading mechanism mainly occurred as noncovalent functionalization at the surface or sidewall of the nanotubes structure and not by intercalation between nanotubes. Similar XRD profiles of the surface functionalized CNTs with biomolecules were also reported by Mehra and Jain [35] and Jain et al. [42].

Raman spectroscopy was used to investigate the structure of SWCNTs before (f-SWCNTs) and after (f-SWCNTs-BA) functionalization with BA. Figure 6 shows the Raman spectra of f-SWCNTs and f-SWCNTs-BA conjugate. The Raman analysis reveals the presence of the radial breathing mode (RBM) and the two characteristic bands of SWCNTs: the socalled G band (tangential mode) and the D band (disorder mode). The RBM of the SWCNTs is generally caused by uniaxial vibrations of the nanotubes and can be observed at 150 and $250 \mathrm{~cm}^{-1}$ (Figure 6(a)). The G band corresponding to the graphitic lattice vibration mode due to stretching of the $\mathrm{C}-\mathrm{C}$ bonds in graphitic plane was displayed at $1571 \mathrm{~cm}^{-1}$ for f-SWCNTs and $1572 \mathrm{~cm}^{-1}$ for f-SWCNTs-BA, respectively. However, the D band was not so obvious in both samples, especially for f-SWCNTs-BA in which the D band could not be detected. This could be due to the noncovalent binding between carbon nanotubes and BA that prevents the formation of defects on the surface of the SWCNTs. On the contrary, covalent functionalization generally will produce significantly larger structural defects resulting in increased intensity of the D band [34]. Overall, the Raman spectra of f-SWCNTs-BA exhibited enhanced intensities of the peaks in comparison to that of f-SWCNTs.

The surface morphology of free BA, f-SWCNTs, and fSWCNTs-BA was observed by FESEM and the images are illustrated in Figure 7. As shown in Figure 7(a), the microstructure of free BA was represented by needle-shaped crystalline particle with a smooth surface. The f-SWCNTs (Figure 7(b)) show tubular-shaped nanoparticles with a smooth surface in a highly aggregated state, whereas the surface morphology of f-SWCNTs-BA (Figure 7(c)) appeared to be rougher and uneven due to the deposition of $\mathrm{BA}$ molecules. The morphology of the f-SWCNTs-BA is fundamentally different from $\mathrm{f}$-SWCNTs, therefore leading to the conclusion that conjugation phenomenon had taken place.

3.2. Loading, Release, and Kinetic Behaviour of Betulinic Acid. The release properties of BA from the f-SWCNTs nanocarrier were evaluated in human body-simulated environment at $\mathrm{pH}$ 7.4 and 4.8 (Figure 8). It was observed that the release rate of BA from f-SWCNTs at $\mathrm{pH} 7.4$ is substantially higher than that at $\mathrm{pH}$ 4.8. This indicates that the $\mathrm{BA}$ release profile from 


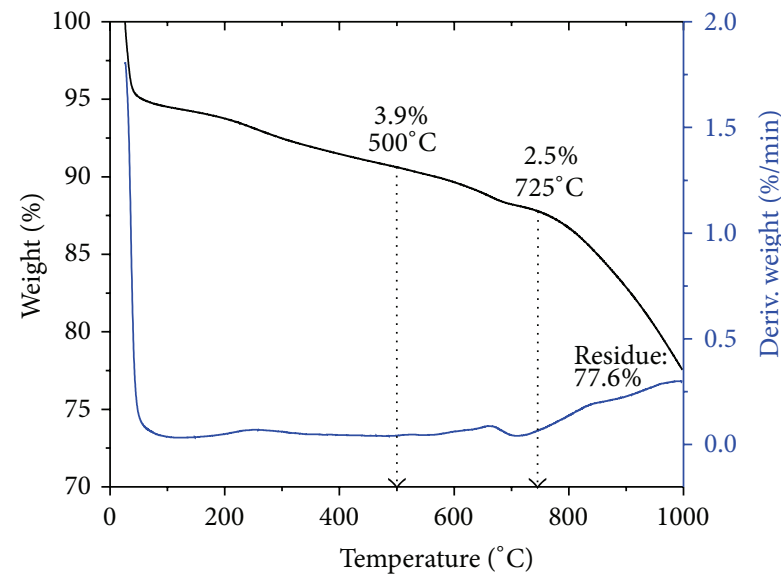

(a)

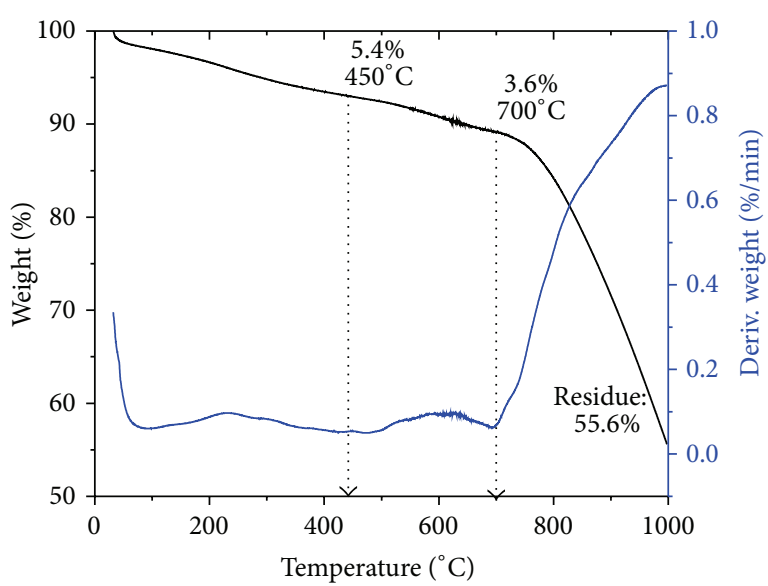

(b)

FIGURE 4: TGA weight loss profiles of (a) f-SWCNTs and (b) f-SWCNTs-BA under nitrogen atmosphere.

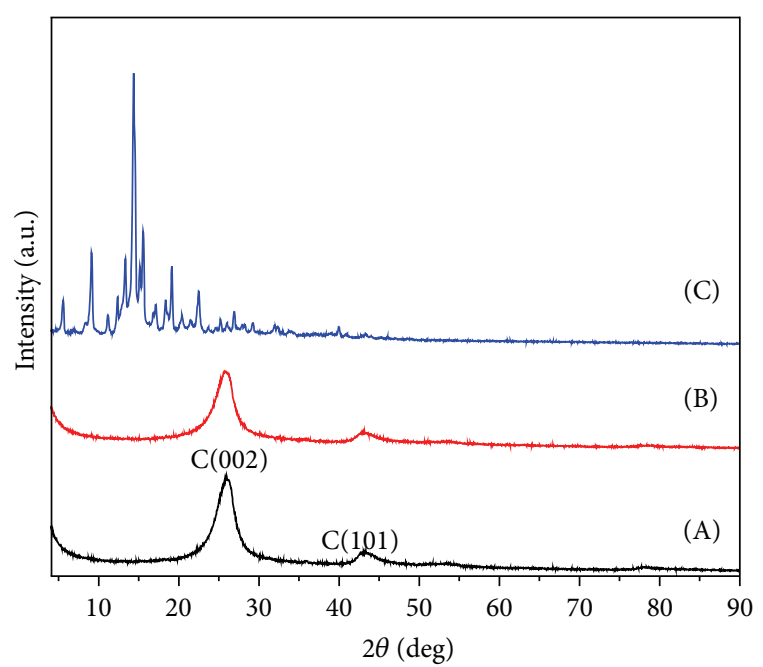

Figure 5: PXRD patterns of (A) f-SWCNTs, (B) f-SWCNTs-BA, and (C) free BA.

SWCNTs is $\mathrm{pH}$-dependent. The maximum percentage release of BA from f-SWCNTs-BA conjugate reached $89.2 \%$ (within 1400 minutes) and $78.7 \%$ (within 600 minutes) when exposed to $\mathrm{pH} 7.4$ and 4.8 , respectively. BA is generally known as a weakly acidic compound with $\mathrm{p} K_{a}$ value of 5.5 [43]. When the $\mathrm{pH}$ of the release medium exceeds the $\mathrm{p} K_{a}$ value of $\mathrm{BA}$, both the $-\mathrm{OH}$ group on $\mathrm{BA}$ and the $-\mathrm{COOH}$ group on $\mathrm{f}-$ SWCNTs would be ionized and, thus, resulting in a higher amount of BA being released into $\mathrm{pH} 7.4$ compared to 4.8 . On the other hand, the slow and sustained release properties of the conjugate might be attributed to the strong repulsive forces that occurred between the carboxylate anions of the nanotubes and BA molecules as well as the anions in the buffer solutions. Hence, these differences in the release rate of the active drug at $\mathrm{pH} 7.4$ and 4.8 are probably due to the different release mechanism of BA from the conjugate as discussed above.

The release in both $\mathrm{pH}$ solutions was very rapid for the first 60 minutes (Figure 8, inset picture) and, thereafter, a more sustained and slower release was observed throughout the experiment. The initial stage of the burst release that occurred in the first 15-20 minutes may be possibly due to the free unloaded drug coated on the surface of the nanotubes. This is generally known as the main cause attributed to surface adhesion and desorption for the burst release of most surface-loaded drugs [44]. Burst release is useful for some medical applications like wound treatment because a fast release in the initial stage would provide immediate pain relief to the patient followed by sustained release to encourage wound healing [45]. However, this phenomenon is also likely to cause unfavourable side effects in drug delivery such as short biological half-life in vivo, frequent dosing due to shortened release profile, and potential systemic/local acute toxicity in human body [46]. In order to circumvent the burst effect of the system, biocompatible polymers such as chitosan could be utilized to form an outer layer through additional coating steps for prolonging the release in the circulation half-life [47]. As such, we are currently conducting further investigation using several biodegradable and biocompatible polymers as well as surfactants for the coating of the conjugate and then study their in vitro drug release profiles.

In order to achieve and maintain the effective therapeutic concentration of the drug in the target tissues for as long as possible, a well-defined behaviour of drug release kinetics is required. For this purpose, mathematical modelling is a very useful method to predict the release kinetics before the drug delivery systems are being realized and, at the same time, it provides important information into the structurefunction relationship of material systems. Generally, the release behaviour can be determined using three different kinetic models, that is, first order (2) [3], pseudo-second order (3) [48], and parabolic diffusion (4) [49]:

$$
\begin{gathered}
\operatorname{In}\left(q_{e}-q_{t}\right)=\operatorname{In} q_{e}-k_{1} t, \\
\frac{t}{q_{t}}=\frac{1}{k_{2} q_{e}^{2}}+\frac{t}{q_{e}}, \\
\frac{\left(1-M_{t} / M_{0}\right)}{t}=k t^{-0.5}+b,
\end{gathered}
$$




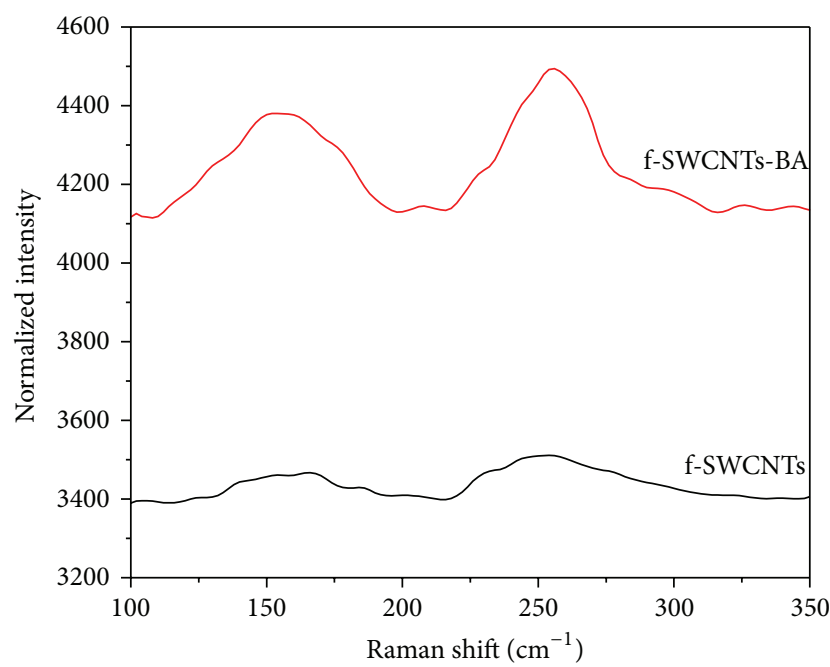

(a)

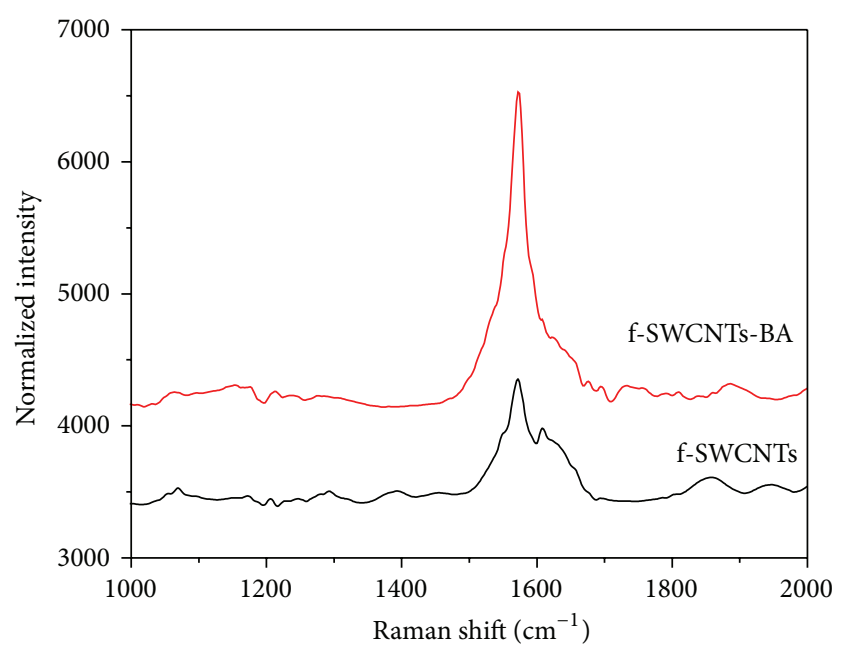

(b)

Figure 6: (a) Raman spectra of the RBM region for f-SWCNTs and f-SWCNTs-BA. (b) Raman spectra D and G bands for f-SWCNTs and f-SWCNTs-BA, respectively.

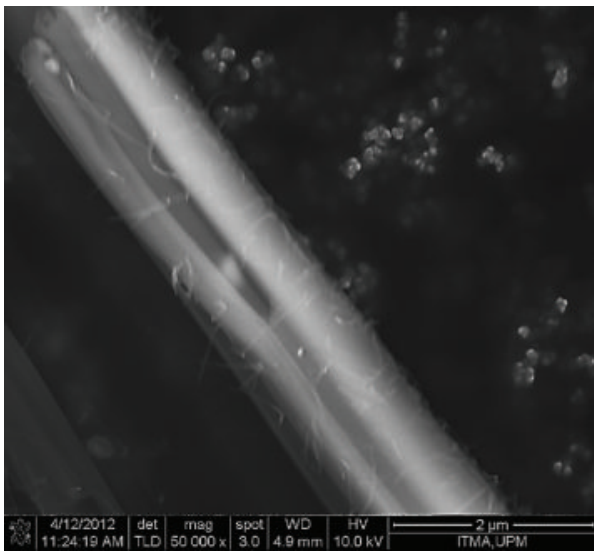

(a)

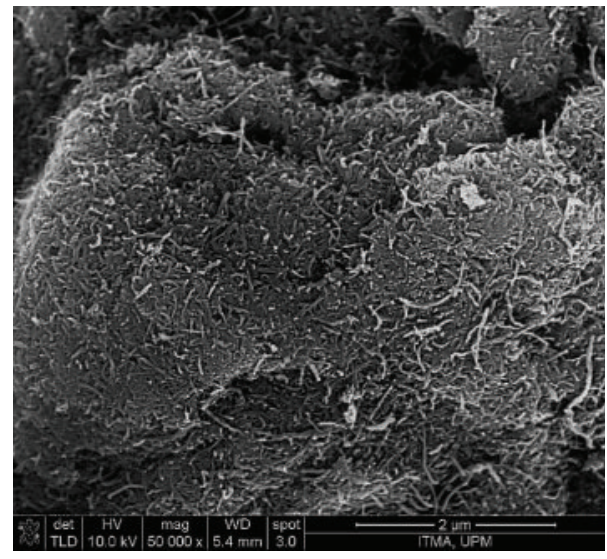

(b)

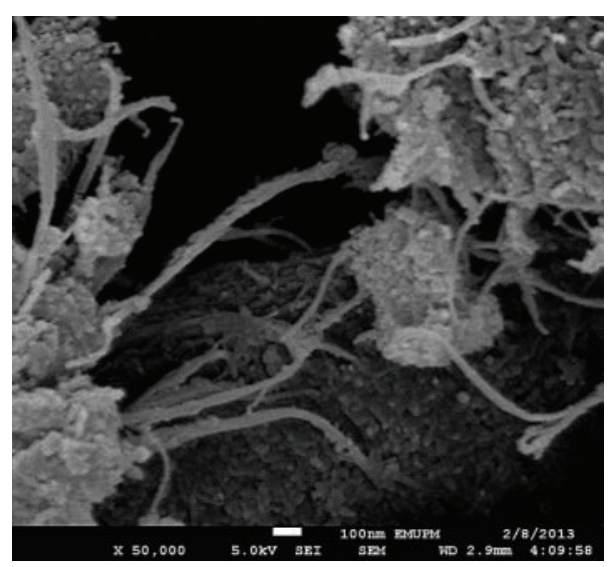

(c)

Figure 7: FESEM images of the surfaces of (a) free BA in its crystalized form, (b) f-SWCNTs, and (c) f-SWCNTs-BA. 
TABLE 1: Correlation coefficient, rate constant, and half-life obtained by fitting the data for release of BA from f-SWCNTs-BA into PBS solutions at $\mathrm{pH} 7.4$ and 4.8 .

\begin{tabular}{|c|c|c|c|c|c|c|}
\hline \multirow{2}{*}{\multicolumn{2}{|c|}{ Aqueous solution Saturated release (\%) }} & \multicolumn{3}{|c|}{$R^{2}$} & \multirow{2}{*}{$\begin{array}{l}\text { Rate constant, } \\
k(\mathrm{mg} / \mathrm{min})\end{array}$} & \multirow{2}{*}{$t_{1 / 2}(\min )$} \\
\hline & & Pseudo-first order & Pseudo-second order & Parabolic diffusion & & \\
\hline pH 7.4 & 89.2 & 0.8817 & 0.9992 & 0.7054 & ${ }^{\mathrm{a}} 3.46 \times 10^{-4}$ & 32 \\
\hline $\mathrm{pH} 4.8$ & 78.7 & 0.2236 & 0.9996 & 0.6421 & ${ }^{\mathrm{a}} 8.15 \times 10^{-4}$ & 15 \\
\hline
\end{tabular}

Note: ${ }^{a}$ estimated using pseudo-second order kinetics.

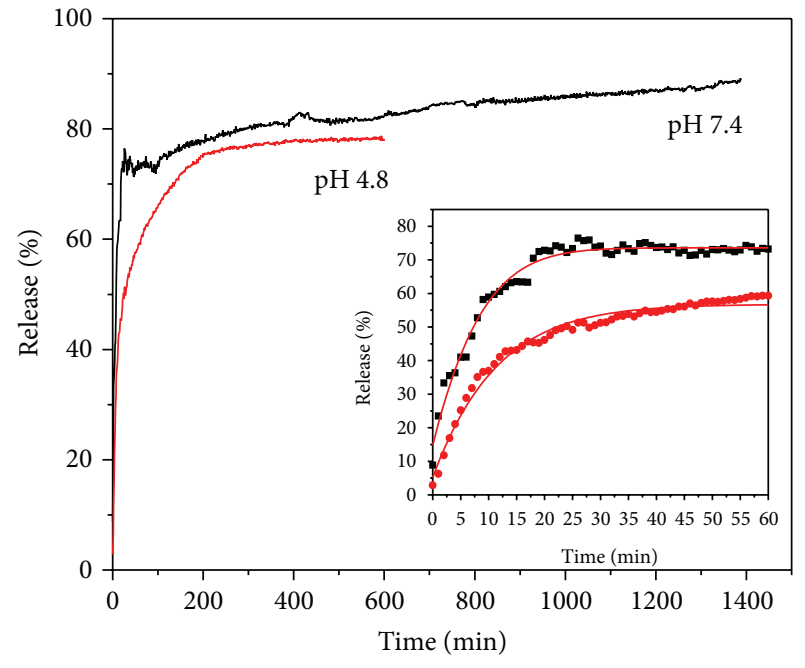

FIGURE 8: Release profiles of BA from f-SWCNTs nanocarrier into $\mathrm{PBS}$ solution at $\mathrm{pH} 7.4$ and 4.8. Inset shows release profiles of $\mathrm{f}$ SWCNTs-BA for the first 60 minutes.

where $q_{e}$ and $q_{t}$ are the equilibrium release rate and the release rate at any time $(t)$, respectively, $k$ is a constant corresponding to release amount, $M_{0}$ and $M_{t}$ represent the drug content remained in the $\mathrm{f}-\mathrm{SWCNTs} \mathrm{BA}$ at release time 0 and $t$, respectively, and $b$ is a constant.

By fitting the release data of the active BA to these kinetic models, it was observed that the release kinetic processes of BA from $\mathrm{f}-\mathrm{SWCNTs-BA}$ conjugate conformed well to pseudo-second order kinetic model for both $\mathrm{pH}$ solutions (Figure 9). At pH 7.4, the release of BA from nanocarrier followed the pseudo-second order equation, with a correlation coefficient of 0.9992 and $k$ value of $3.46 \times 10^{-4} \mathrm{mg}$ per minute. For PBS solution at $\mathrm{pH} 4.8$, the release kinetics of BA also fits better to the pseudo-second order model (correlation coefficient of 0.9996 and $k$ value of $8.15 \times 10^{-4} \mathrm{mg}$ per minute). Table 1 demonstrates the time release profile for BA in PBS solutions at pH 7.4 and 4.8, respectively. The second order release kinetics indicates that the release of BA is concentration-dependent and the half-life increases as the initial concentration of $\mathrm{BA}$ is increased. The reaction rate observed in this study can be considered as a moderate type [50] with time span over $1000 \mathrm{~min}$ for a complete drug release.

3.3. Cytotoxicity Evaluation. Figure 10 shows the effect of free BA, f-SWCNTs nanocarrier, and f-SWCNTs-BA conjugate on cytotoxicity of 3T3 cells (Figure 10(a)), HepG2 cells (Figure 10(b)), and A549 cells (Figure 10(c)) at various concentrations, ranging from 0.78 to $50 \mu \mathrm{g} / \mathrm{mL}$ at 72 hours' time point using MTT assay. In vitro cytotoxicity analysis is a commonly used approach to evaluate the biocompatibility of the synthesized nanomaterial for a biomedical application. Therefore, we investigated the cytotoxic effect of the free BA, the nanocarrier, and the f-SWCNTs-BA conjugate concentrations in a healthy fibroblast cell line (3T3) and two human cancer cell lines (HepG2 and A549), respectively.

As shown in Figure 10(a), the 3T3 cell viability of free BA was reduced to approximately $25 \%$ when the concentration exceeded $50 \mu \mathrm{g} / \mathrm{mL}$. Although BA is a very promising therapeutic compound as discussed before, it has an implicit low toxicity when compared to other chemotherapy drugs like camptothecin, taxol, vincristine, and vinblastine [51]. Furthermore, 3T3 cell line is a very sensitive in vitro model commonly used for the detection of carcinogenic potential of chemicals and, hence, low cytotoxic effect of BA may cause the significant reduction in $3 \mathrm{~T} 3$ viable cells when applied at high concentration $(50 \mu \mathrm{g} / \mathrm{mL})$. For the nanocarrier, the cell viability was dramatically reduced to about $40 \%$ when the concentration was more than $50 \mu \mathrm{g} / \mathrm{mL}$. This is mainly attributed to the physicochemical property of CNTs in which when further diluted into the cell culture media they tend to rapidly reaggregate into bundles due to strong van der Waals interaction. On the other hand, the resulting conjugate at concentrations from 0.78 to $25 \mu \mathrm{g} / \mathrm{mL}$ did not express any cytotoxicity after 72 hours of treatment, but the cells exposed to $50 \mu \mathrm{g} / \mathrm{mL}$ showed more than $50 \%$ reduction in cell viability. This could be due to the effect of the BA in which the BA compound showed a significant reduction of $80 \%$ in cell viability when the concentration exceeded $50 \mu \mathrm{g} / \mathrm{mL}$. In general, we observed higher cell viability for f-SWCNTs-BA conjugate in comparison with the nanocarrier or with the free BA after 72 hours of treatment.

Figures 10(b) and 10(c) show that exposure to free BA, f-SWCNTs, and f-SWCNTs-BA at doses ranging from 0.78 to $50 \mu \mathrm{g} / \mathrm{mL}$ caused a dose-dependent cytotoxicity manner in both liver and lung cancer cells. The conjugate exhibited greater anticancer activity at lower dosages in A549 cells compared to HepG 2 cells. It is also important to be noted that, even though the same concentrations of BA and f-SWCNTsBA were used in this study, only about $20-22 \%$ of the drug was actually loaded in the conjugate. This indicates that the conjugate can achieve better therapeutic effect of killing the cancer cells with only $20-22 \%$ of BA in comparison with pure BA (100\%). With the reduction of the drug dosage, many unwanted side effects of the drug can be further minimized, especially in cancer-related treatments. 


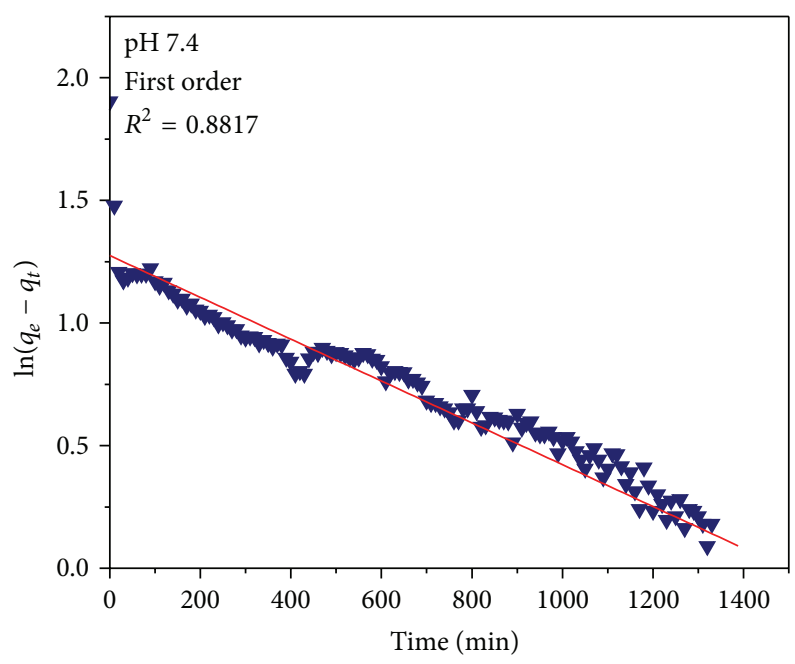

(a)

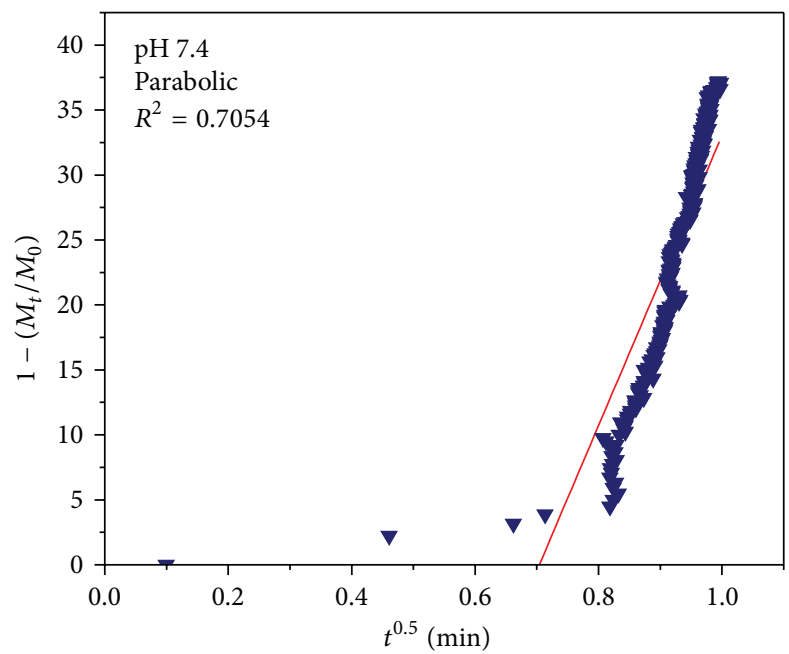

(c)

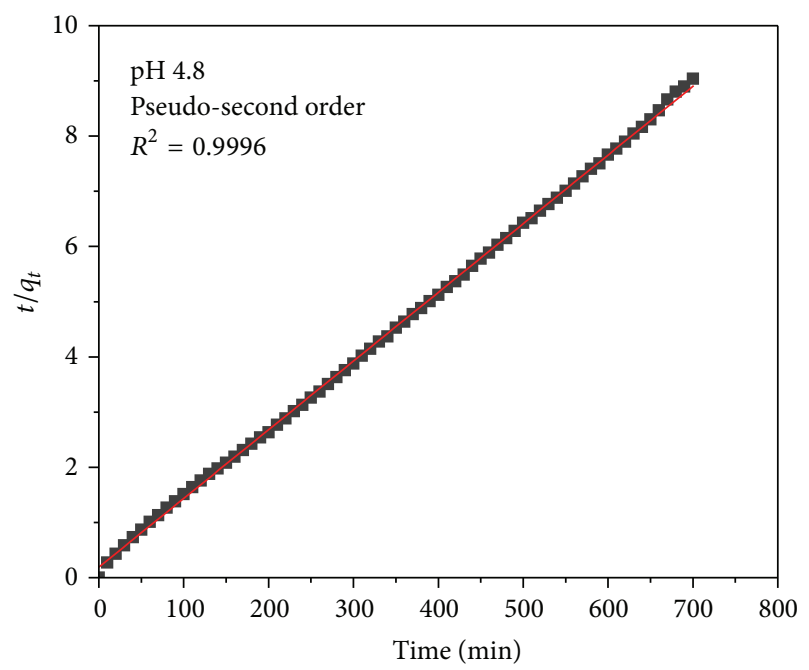

(e)

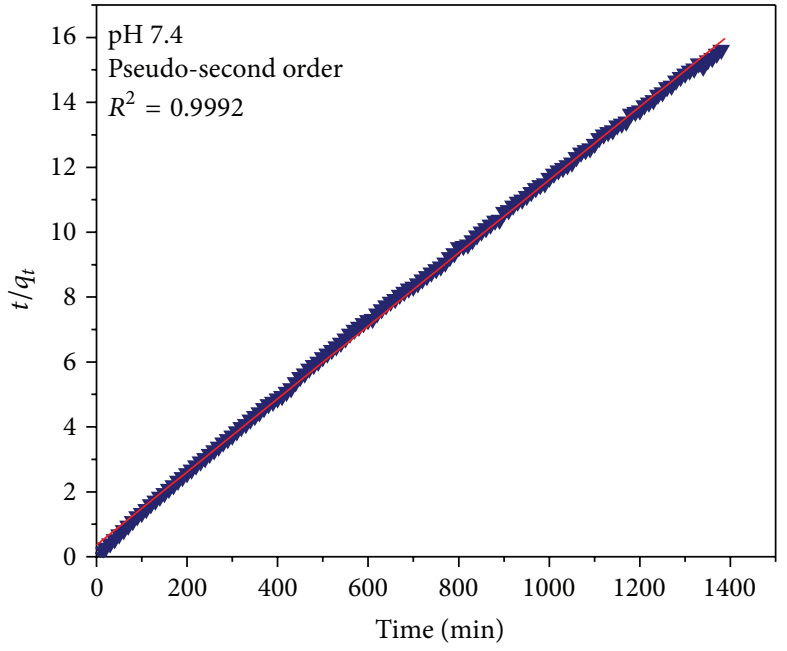

(b)

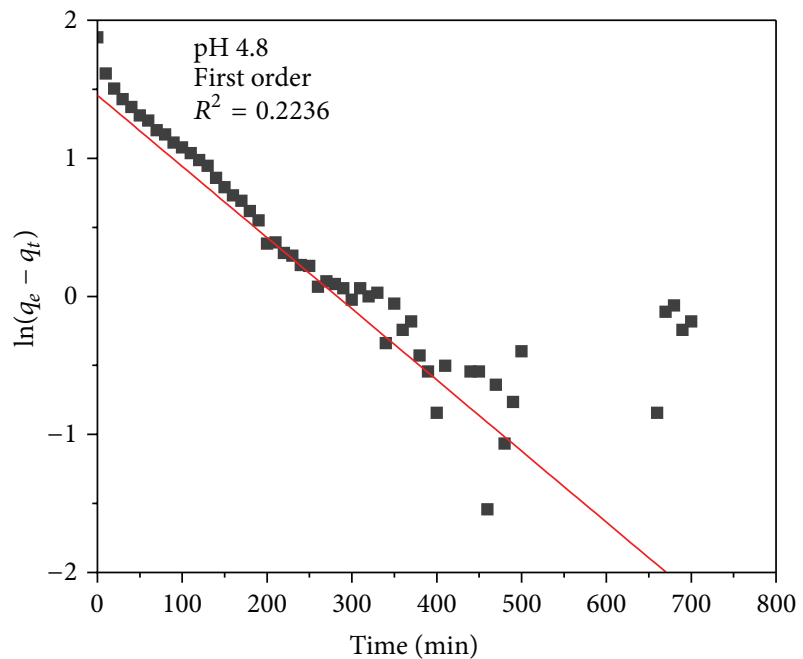

(d)

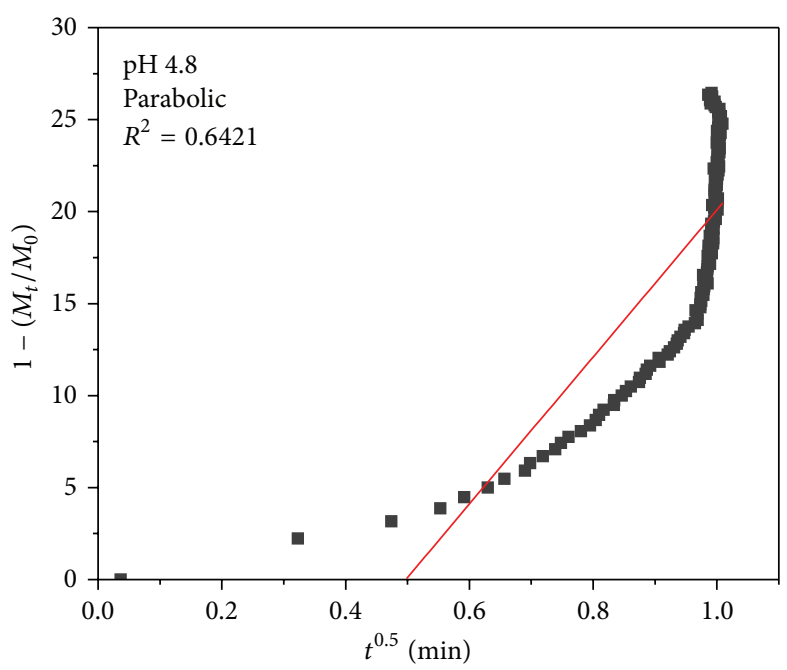

(f)

FIGURE 9: Fitting the data for BA released from f-SWCNTs nanocarrier into PBS solutions with specific $\mathrm{pH}$ values. 


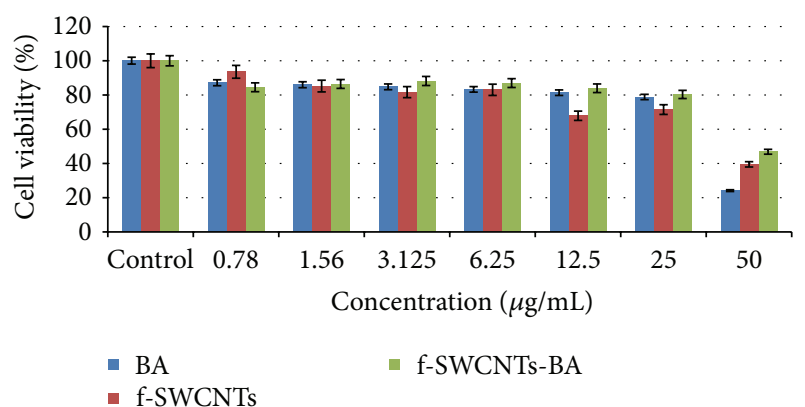

(a)

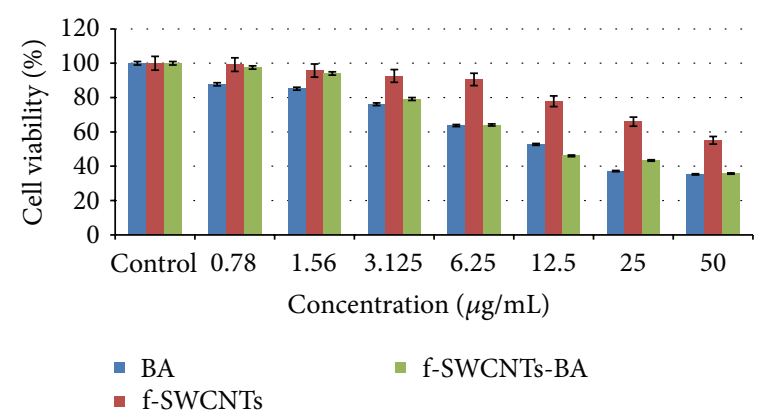

(b)

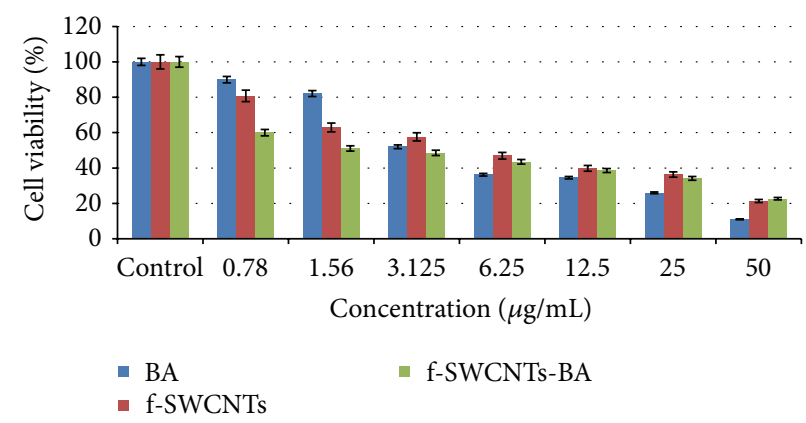

(c)

FIGURE 10: In vitro cytotoxicity study of (a) 3T3, (b) HepG2, and (c) A549 exposed to free BA, f-SWCNTs nanocarrier, and the f-SWCNTs-BA conjugate, respectively, at various concentrations after $72 \mathrm{~h}$ of treatment. The data presented are mean \pm SD of triplicate values.

\section{Conclusions}

In summary, we have successfully synthesized a controlled and sustained release formulation of BA noncovalently loaded to f-SWCNTs as drug delivery system conjugate. FTIR analysis of the conjugate demonstrated the presence of functional groups of both BA and the nanocarrier, indicating that the drug was loaded onto the f-SWCNTs. This result is further confirmed by Raman spectroscopy studies. The loading of BA onto the nanocarrier was estimated to be about $20 \%(\mathrm{w} / \mathrm{w})$ and this value is in agreement with the TGA study. Powder $\mathrm{XRD}$ analysis showed that the structure of the functionalized nanotubes was unaffected by the loading of drug BA. The release of BA from nanocarrier was observed to occur in a controlled manner governed by the different levels of $\mathrm{pH}$ in the release medium and, therefore, this drug carrier could be further developed as a controlled release formulation with a prolonged release property. Pseudo-second order model was found to be the best to describe the release kinetic process of BA from the nanocarrier at both pH levels 7.4 and 4.8 in comparison to the other models. Although the burst effect of BA would most likely be the limiting factor for therapeutic use in controlled delivery applications, additional coating steps for prolonging the release in the circulation half-life using biocompatible polymers are currently underway. The cytotoxicity study demonstrated a decrease in the toxicity potential of the conjugate in a normal cell line but enhanced anticancer activity in both human cancer cell lines. Further investigations in terms of specific cellular mechanism of the resulting conjugate are required to elucidate the conjugate interaction with cells prior to in vivo biological studies involving animal models. The results from this preliminary finding indicate that the synthesized conjugate $(\sim 20-22 \%$ of loaded BA) has the potential to be developed as the drug delivery system for BA since it demonstrated less cytotoxicity but enhanced anticancer activity than free BA (100\% of BA). By reducing the drug dosage, this means causing less harm to the normal cells and, thus, provides a better healthcare and well-being in patient.

\section{Conflict of Interests}

The authors confirm that they have no financial and personal interests in the work described.

\section{Acknowledgments}

This research was substantially supported by a grant from the Ministry of Education of Malaysia (MOE) under Grant no. GP-IPB/2013/9425800 and MyPhD scholarship under the MyBrain15 program for Julia M. Tan.

\section{References}

[1] E. M. M. Del Valle, M. A. Galán, and R. G. Carbonell, "Drug delivery technologies: the way forward in the new decade," Industrial and Engineering Chemistry Research, vol. 48, no. 5, pp. 2475-2486, 2009.

[2] R. Hariharan, S. Senthilkumar, A. Suganthi, and M. Rajarajan, "Synthesis and characterization of doxorubicin modified $\mathrm{ZnO} / \mathrm{PEG}$ nanomaterials and its photodynamic action," Journal 
of Photochemistry and Photobiology B: Biology, vol. 116, pp. 5665, 2012.

[3] B. Saifullah, M. Z. Hussein, S. H. Hussein-Al-Ali, P. Arulselvan, and S. Fakurazi, "Antituberculosis nanodelivery system with controlled-release properties based on para-amino salicylatezinc aluminum-layered double-hydroxide nanocomposites," Drug Design, Development and Therapy, vol. 7, pp. 1365-1375, 2013.

[4] B. S. Wong, S. L. Yoong, A. Jagusiak et al., "Carbon nanotubes for delivery of small molecule drugs," Advanced Drug Delivery Reviews, vol. 65, no. 15, pp. 1964-2015, 2013.

[5] E. A. Teunissen, M. de Raad, and E. Mastrobattista, "Production and biomedical applications of virus-like particles derived from polyomaviruses," Journal of Controlled Release, vol. 172, no. 1, pp. 305-321, 2013.

[6] Q. Zeng, H. Wen, Q. Wen et al., "Cucumber mosaic virus as drug delivery vehicle for doxorubicin," Biomaterials, vol. 34, no. 19, pp. 4632-4642, 2013.

[7] J. J. Salomon and C. Ehrhardt, "Organic cation transporters in the blood-air barrier: expression and implications for pulmonary drug delivery," Therapeutic Delivery, vol. 3, no. 6, pp. 735-747, 2012.

[8] C. L. Tseng, K. H. Chen, W. Y. Su, Y. H. Lee, C. C. Wu, and F. H. Lin, "Cationic gelatin nanoparticles for drug delivery to the ocular surface: in vitro and in vivo evaluation," Journal of Nanomaterials, vol. 2013, Article ID 238351, 11 pages, 2013.

[9] W. Teng, J. Cappello, and X. Wu, "Physical crosslinking modulates sustained drug release from recombinant silk-elastinlike protein polymer for ophthalmic applications," Journal of Controlled Release, vol. 156, no. 2, pp. 186-194, 2011.

[10] M. Hofer, G. Winter, and J. Myschik, "Recombinant spider silk particles for controlled delivery of protein drugs," Biomaterials, vol. 33, no. 5, pp. 1554-1562, 2012.

[11] J. Cheng, M. J. Meziani, Y.-P. Sun, and S. H. Cheng, "Poly(ethylene glycol)-conjugated multi-walled carbon nanotubes as an efficient drug carrier for overcoming multidrug resistance," Toxicology and Applied Pharmacology, vol. 250, no. 2, pp. 184-193, 2011.

[12] R. Li, R. Wu, L. Zhao et al., "Folate and iron difunctionalized multiwall carbon nanotubes as dual-targeted drug nanocarrier to cancer cells," Carbon, vol. 49, no. 5, pp. 1797-1805, 2011.

[13] Z. Ji, G. Lin, Q. Lu et al., “Targeted therapy of SMMC-7721 liver cancer in vitro and in vivo with carbon nanotubes based drug delivery system," Journal of Colloid and Interface Science, vol. 365, no. 1, pp. 143-149, 2012.

[14] X. Zheng, T. Wang, H. Jiang et al., "Incorporation of carvedilol into PAMAM-functionalized MWNTs as a sustained drug delivery system for enhanced dissolution and drug-loading capacity," Asian Journal of Pharmaceutical Sciences, vol. 8, pp. 278-286, 2013.

[15] X. Luo, C. Matranga, S. Tan, N. Alba, and X. T. Cui, "Carbon nanotube nanoreservior for controlled release of anti-inflammatory dexamethasone," Biomaterials, vol. 32, no. 26, pp. 63166323, 2011.

[16] Z. Liu, K. Chen, C. Davis et al., "Drug delivery with carbon nanotubes for in vivo cancer treatment," Cancer Research, vol. 68, no. 16, pp. 6652-6660, 2008.

[17] T.-J. Park, Y. S. Kim, T. Hwang et al., "Preparation and characterization of heparinized multi-walled carbon nanotubes," Process Biochemistry, vol. 47, no. 1, pp. 113-118, 2012.
[18] S. Park, J. Shin, J. Lee, and M. Cha, "Manipulation of NIH3T3 cells with functionalized single-walled carbon nanotubes under a magnetic field," Materials Letters, vol. 68, pp. 378-381, 2012.

[19] X. Liu, H. Tao, K. Yang, S. Zhang, S.-T. Lee, and Z. Liu, "Optimization of surface chemistry on single-walled carbon nanotubes for in vivo photothermal ablation of tumors," Biomaterials, vol. 32, no. 1, pp. 144-151, 2011.

[20] P. Yogeeswari and D. Sriram, "Betulinic acid and its derivatives: a review on their biological properties," Current Medicinal Chemistry, vol. 12, no. 6, pp. 657-666, 2005.

[21] L. C. Baratto, M. V. Porsani, I. C. Pimentel, A. B. P. Netto, R. Paschke, and B. H. Oliveira, "Preparation of betulinic acid derivatives by chemical and biotransformation methods and determination of cytotoxicity against selected cancer cell lines," European Journal of Medicinal Chemistry, vol. 68, pp. 121-131, 2013.

[22] M. Jain, R. Kapadia, R. N. Jadeja, M. C. Thounaojam, R. V. Devkar, and S. H. Mishra, "Hepatoprotective potential of Tecomella undulata stem bark is partially due to the presence of betulinic acid," Journal of Ethnopharmacology, vol. 143, no. 1, pp. 194-200, 2012.

[23] M. A. Nader and H. N. Baraka, "Effect of betulinic acid on neutrophil recruitment and inflammatory mediator expression in lipopolysaccharide-induced lung inflammation in rats," European Journal of Pharmaceutical Sciences, vol. 46, no. 1-2, pp. 106113, 2012.

[24] Z. Dang, K. Qian, P. Ho et al., "Synthesis of betulinic acid derivatives as entry inhibitors against HIV-1 and bevirimatresistant HIV-1 variants," Bioorganic and Medicinal Chemistry Letters, vol. 22, no. 16, pp. 5190-5194, 2012.

[25] J. K. Adesanwo, O. O. Makinde, and C. A. Obafemi, "Phytochemical analysis and antioxidant activity of methanol extract and betulinic acid isolated from the roots of Tetracera potatoria," Journal of Pharmacy Research, vol. 6, no. 9, pp. 903-907, 2013.

[26] H. Kommera, G. N. Kaluderović, S. Dittrich et al., "Carbamate derivatives of betulinic acid and betulin with selective cytotoxic activity," Bioorganic and Medicinal Chemistry Letters, vol. 20, no. 11, pp. 3409-3412, 2010.

[27] S. Chintharlapalli, S. Papineni, P. Lei, S. Pathi, and S. Safe, "Betulinic acid inhibits colon cancer cell and tumor growth and induces proteasome-dependent and -independent downregulation of specificity proteins ( $\mathrm{Sp}$ ) transcription factors," $B M C$ Cancer, vol. 11, article 371, 2011.

[28] T. Reiner, R. Parrondo, A. de las Pozas, D. Palenzuela, and C. Perez-Stable, "Betulinic acid selectively increases protein degradation and enhances prostate cancer-specific apoptosis: possible role for inhibition of deubiquitinase activity," PLoS ONE, vol. 8, no. 2, Article ID e56234, 2013.

[29] Y.-F. Sun, C.-K. Song, H. Viernstein, F. Unger, and Z.-S. Liang, "Apoptosis of human breast cancer cells induced by microencapsulated betulinic acid from sour jujube fruits through the mitochondria transduction pathway," Food Chemistry, vol. 138, no. 2-3, pp. 1998-2007, 2013.

[30] E. Selzer, E. Pimentel, V. Wacheck et al., "Effects of betulinic acid alone and in combination with irradiation in human melanoma cells," Journal of Investigative Dermatology, vol. 114, no. 5, pp. 935-940, 2000.

[31] S.-T. Yang, W. Guo, Y. Lin et al., "Biodistribution of pristine single-walled carbon nanotubes in vivo," The Journal of Physical Chemistry C, vol. 111, no. 48, pp. 17761-17764, 2007.

[32] R. Singh, D. Pantarotto, L. Lacerda et al., “Tissue biodistribution and blood clearance rates of intravenously administered carbon 
nanotube radiotracers," Proceedings of the National Academy of Sciences of the United States of America, vol. 103, no. 9, pp. 33573362, 2006.

[33] H. R. Darabi, M. J. Tehrani, K. Aghapoor, F. Mohsenzadeh, and R. Malekfar, "A new protocol for the carboxylic acid sidewall functionalization of single-walled carbon nanotubes," Applied Surface Science, vol. 258, no. 22, pp. 8953-8958, 2012.

[34] C. Dong, A. S. Campell, R. Eldawud, G. Perhinschi, Y. Rojanasakul, and C. Z. Dinu, "Effects of acid treatment on structure, properties and biocompatibility of carbon nanotubes," Applied Surface Science, vol. 264, pp. 261-268, 2013.

[35] N. K. Mehra and N. K. Jain, "Development, characterization and cancer targeting potential of surface engineered carbon nanotubes," Journal of Drug Targeting, vol. 21, no. 8, pp. 745-758, 2013.

[36] J. Fan, F. Zeng, J. Xu, and S. Wu, “Targeted anti-cancer prodrug based on carbon nanotube with photodynamic therapeutic effect and $\mathrm{pH}$-triggered drug release," Journal of Nanoparticle Research, vol. 15, no. 9, article 1911, 2013.

[37] A. U. Kura, S. H. H. A. Ali, M. Z. Hussein, S. Fakurazi, and P. Arulselvan, "Development of a controlled-release anti-parkinsonian nanodelivery system using levodopa as the active agent," International Journal of Nanomedicine, vol. 8, pp. 1103-1110, 2013.

[38] D. Dorniani, M. Z. Hussein, A. U. Kura, S. Fakurazi, A. H. Shaari, and Z. Ahmad, "Preparation and characterization of 6-mercaptopurine-coated magnetite nanoparticles as a drug delivery system," Drug Design, Development and Therapy, vol. 7, pp. 1015-1026, 2013.

[39] J. M. Tan, G. Karthivashan, P. Arulselvan, S. Fakurazi, and M. Z. Hussein, "Characterization and in vitro sustained release of silibinin from $\mathrm{pH}$ responsive carbon nanotube-based drug delivery system," Journal of Nanomaterials, vol. 2014, Article ID 439873, 10 pages, 2014.

[40] S. Cĭntă-Pı̌nzaru, C. A. Dehelean, C. Soica, M. Culea, and F. Borcan, "Evaluation and differentiation of the Betulaceae birch bark species and their bioactive triterpene content using analytical FT-vibrational spectroscopy and GC-MS," Chemistry Central Journal, vol. 6, no. 1, article 67, 2012.

[41] G. Vuković, A. Marinković, M. Obradović et al., "Synthesis, characterization and cytotoxicity of surface amino-functionalized water-dispersible multi-walled carbon nanotubes," Applied Surface Science, vol. 255, no. 18, pp. 8067-8075, 2009.

[42] A. K. Jain, V. Dubey, N. K. Mehra et al., "Carbohydrateconjugated multiwalled carbon nanotubes: development and characterization," Nanomedicine: Nanotechnology, Biology, and Medicine, vol. 5, no. 4, pp. 432-442, 2009.

[43] H. Du and X. Chen, "CD-MEKC method to analyze triterpene acids in traditional Chinese medicines," Journal of the Brazilian Chemical Society, vol. 20, no. 7, pp. 1268-1274, 2009.

[44] Y. Yeo and K. Park, "Control of encapsulation efficiency and initial burst in polymeric microparticle systems," Archives of Pharmacal Research, vol. 27, no. 1, pp. 1-12, 2004.

[45] J. A. Setterstrom, T. R. Tice, W. E. Meyers, and J. W. Vincent, "Development of encapsulated antibiotics for topical administration to wounds," in Recent Advances in Drug Delivery Systems, pp. 185-198, 1984.

[46] X. Huang and C. S. Brazel, "On the importance and mechanisms of burst release in matrix-controlled drug delivery systems," Journal of Controlled Release, vol. 73, no. 2-3, pp. 121-136, 2001.

[47] S. C. Vasudev, T. Chandy, and C. P. Sharma, "Development of chitosan/polyethylene vinyl acetate co-matrix: controlled release of aspirin-heparin for preventing cardiovascular thrombosis," Biomaterials, vol. 18, no. 5, pp. 375-381, 1997.

[48] Y.-S. Ho and A. E. Ofomaja, "Pseudo-second-order model for lead ion sorption from aqueous solutions onto palm kernel fiber," Journal of Hazardous Materials, vol. 129, no. 1-3, pp. 137142, 2006.

[49] L. Dong, L. Yan, W.-G. Hou, and S.-J. Liu, "Synthesis and release behavior of composites of camptothecin and layered double hydroxide," Journal of Solid State Chemistry, vol. 183, no. 8, pp. 1811-1816, 2010.

[50] M. R. Wright, An Introduction to Chemical Kinetics, John Wiley \& Sons, London, UK, 2004.

[51] J. Patočka, "Biologically active pentacyclic triterpenes and their current medicine signification," Journal of Applied Biomedicine, vol. 10, no. 3, pp. 7-12, 2003. 

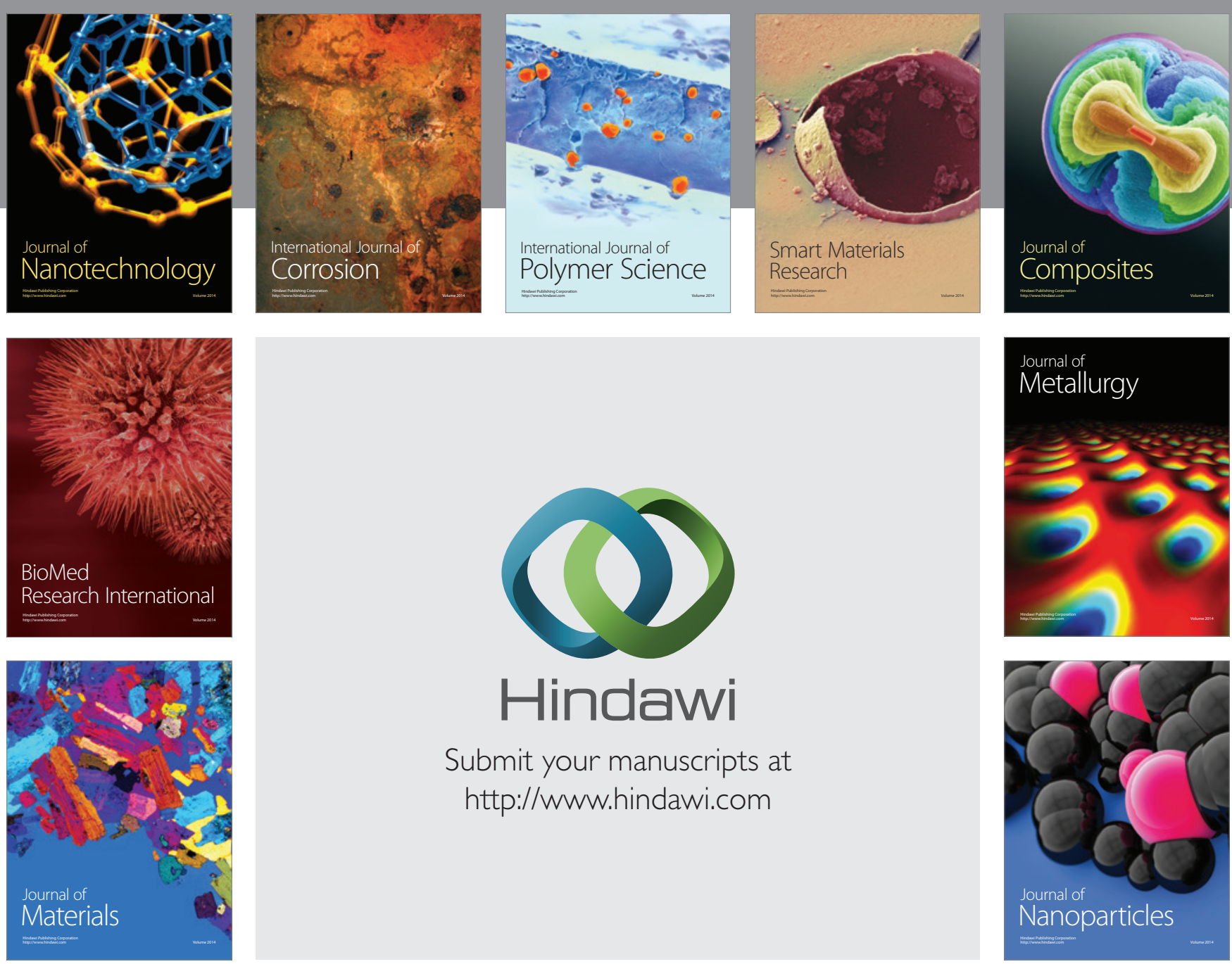

Submit your manuscripts at http://www.hindawi.com
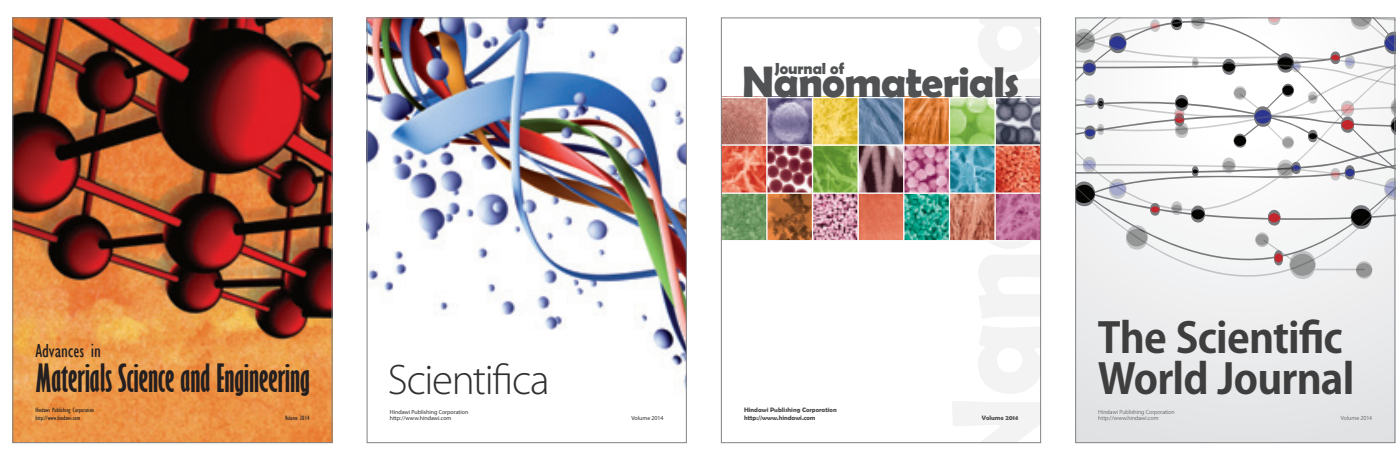

\section{The Scientific World Journal}
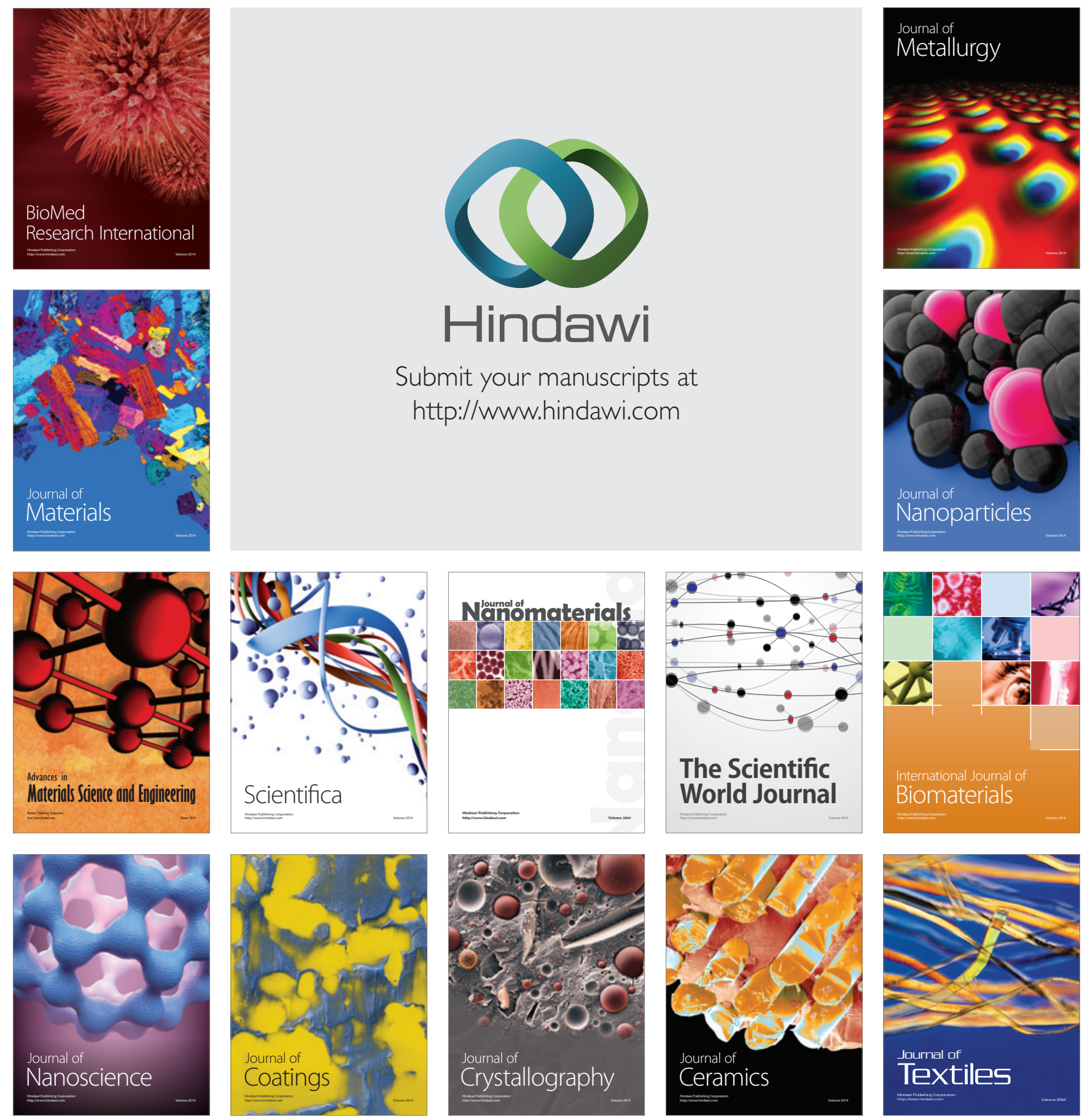